\title{
The promise of vascular reparative therapy in standby mode. How long before a final decision? Complete vessel wall regeneration and vascular scaffold resorption after left anterior descending reconstructions
}

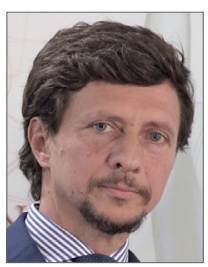

Flavio L. Ribichini*, MD; Gabriele Pesarini, MD

Division of Cardiology, Department of Medicine, University of Verona, Verona, Italy

Mankind has a natural propensity to dream, develop and change, as these are the bases of evolution. Accepting changes takes quite a long time since the perception of evolution is not part of daily life, and only its final result can be recognised as tangible change. Most evolutional changes span generations; therefore, science and culture serve as the only witnesses and archivers of change.

Accepting change in medicine relies on scientific evidence. We obtain it through scientific method: a verification of the evolutional value of the change itself. Not infrequently, the scientific method discourages ideas and expectations that do not lead to a real or measurable change, but often also strengthens those that actually do. Thus, science contributes to a certain step-by-step "development" of evolution.

The possibility of a "biologic reconstruction" of the arterial wall in patients with advanced atherosclerosis (the most common cause of death in humans) with fully bioresorbable vascular scaffolds (BVS) has been hypothesised as being an ultimate goal in vascular biology. This concept could fully qualify as a step forward in evolution when compared to the present standards of permanent endovascular metallic prostheses. However, the expectations raised by the first-generation BVS (Absorb ${ }^{\mathrm{TM}}$; Abbott Vascular, Santa Clara, CA, USA) have recently been questioned by the lack of clear value of the "bioresorbable concept" in daily practice on the one hand, and by the observation of inferior clinical performance compared to the present standards on the other. Indeed, a higher incidence of scaffold thrombosis and target vessel-related myocardial infarction emerged from clinical trials ${ }^{1}$ and has recently been confirmed by the authors of the AIDA trial published in this issue of EuroIntervention ${ }^{2}$, casting doubt on the future of the expected "bioresorbable revolution" in vascular interventions.

\section{Article, see page 426}

Several hypotheses have been proposed to explain the unfavourable events observed at mid to long term, just when the theoretical advantages were supposed to become evident ${ }^{3}$. Among others, probably the easiest to understand, to address and correct relates to the implantation technique that, as historically seen in firstgeneration drug-eluting stents (DES), continues to be an evolving determinant for the performance of newer endovascular devices ${ }^{4}$. However, almost 15 years ago, the movement towards "zero restenosis" was also a goal in the evolutionary process and, even if biologically unlikely, it was expected and believed to be true. Today it is acknowledged that restenosis of DES is not zero, but DES have remained and represent a solid step forward in the evolution of minimally invasive medicine. Similarly, the movement towards the "bioresorbable concept" has put BVS under trial, and the vascular restoration therapy (VRT) concept awaits final judgement.

*Corresponding author: Department of Medicine, University of Verona, Piazzale Aristide Stefani 1, 37126 Verona, Italy. 
The importance of the implantation technique has once again emerged as a possible determinant of the clinical outcome of endovascular interventions with BVS, mainly at short to mid term $^{4}$, although the mechanisms involved in late BVS thrombosis, after the partial disintegration of the polymer, are more complex and may involve causes other than just the mechanical effects of a suboptimal vessel predilatation, scaffold expansion, and apposition, as demonstrated by the authors of the AIDA trial ${ }^{5}$.

\section{Article, see page 434}

Indeed, an accurate monitoring of the long-term performance of BVS is mandatory to understand the role of scaffold sizing, antithrombotic therapy and the chemical effects on the vascular wall biology of the polymer degradation in the long-term safety and efficacy of VRT.

IT-DISAPPEARS, a nationwide Italian registry focused on the treatment of diffuse coronary lesions with BVS, was designed and performed with the aim (and hope) of "restoring" diffusely infiltrated atherosclerotic vessels in the long term, using a meticulous implantation technique ${ }^{6}$. IT-DISAPPEARS enrolled 1,000 patients who typically exhibit suboptimal benefits from current DES technology, which requires implantation of long metallic stents.
The study has so far yielded good clinical results at mid term ${ }^{7}$, and the first treated cases are becoming subjects for analysis of the original VRT concept at long term.

Beyond the controversies raised by implantation details or other theoretical considerations, we present two cases that illustrate the VRT concept: the first is a young diabetic patient presenting an acute total occlusion of a diffusely atherosclerotic left anterior descending artery (LAD) and ST-elevation myocardial infarction; the second is a young patient with angina at rest and troponin rise as the first manifestation of his diffuse coronary artery disease (CAD). These forms of CAD are clear examples of the "unmet needs" of conventional current revascularisation options: coronary bypass surgery and/or full vessel coverage with metallic stent platforms.

Our first patient underwent a total LAD reconstruction with implantation of two long BVS from the ostium of the vessel as the preferred approach of a primary angioplasty in acute infarction. The follow-up, obtained electively five years later, shows the proof of concept of maintaining an anatomically and biologically "normal" artery without metallic foreign bodies in a young diabetic male with diffuse CAD (Figure 1). Before discharge, the distal left circumflex artery and the distal right coronary artery were

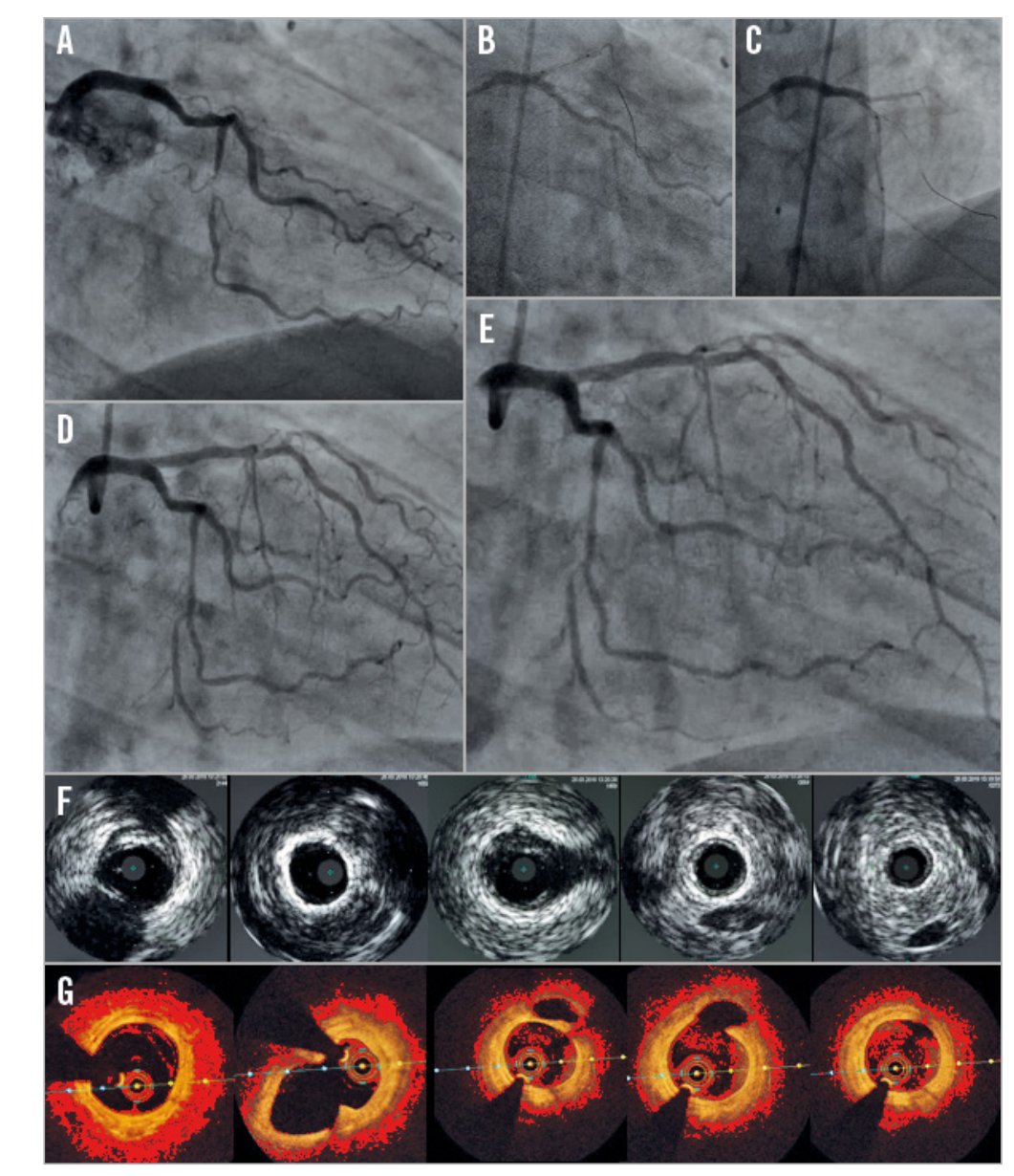

Figure 1. Complete LAD reconstruction in STEMI and long-term follow-up. Coronary angiogram showing the total occlusion of the proximal $L A D$ in anterior STEMI (A); implantation of two BVS $(3.5 \times 28 \mathrm{~mm}$ and $3.0 \times 28 \mathrm{~mm})$ from the ostium of the LAD $(B$ \& $C)$; angiographic result on the LAD (D). Five-year follow-up: angiography (E), IVUS (F) and OCT (G). 
also treated with a drug-eluting balloon and a BVS, respectively, with optimal angiographic results at five-year follow-up (images not shown).

The second patient presented with a subocclusion of a diffusely atherosclerotic LAD and was discussed by the Heart Team. The cardiologists considered the limitations expected mid to long term when implanting multiple metallic DES, while the surgeons underlined the suboptimal quality of the native vessel for a single bypass graft in a young patient (aged 41) who may need subsequent interventions on this and other vessels. The patient, discussed in April 2014, was considered an "optimal candidate" for a full endovascular reconstruction of the LAD with the implantation of multiple BVS. Before treatment, the vessel was visualised by intravascular ultrasound (IVUS), with clear demonstration of the extensive atherosclerotic infiltration of the arterial wall throughout the vessel. IVUS was also used to assess the final result of the multiple BVS implantation. The procedure was performed uneventfully, and the patient was discharged 48 hours later with directions to follow an out-patient clinic follow-up programme for secondary prevention. All clinical controls were negative, including stress test and a stress perfusion study after one year.

After almost four years, while the patient was experiencing a totally normal lifestyle for a 45 -year old man, an invasive follow-up was performed electively (Figure 2).
Up to the point of BVS introduction, the images shown in this article were rarely observed in daily practice. Certainly, it was premature for device manufacturers to propose routine use of BVS. Cardiologists who believed in the potential of BVS and embraced the "bioresorbable concept" adopted its use more out of wishful thinking than solid scientific evidence. Now, as cases like those presented above become available (in spite of being only spot observations), they illustrate the "proof of concept" that primed the initial enthusiasm for this new therapeutic option. It is indeed a new perspective that preserves all of its potential for completely upsetting the status quo of coronary interventions and represents a slow and sustained evolutional change ${ }^{8}$, albeit at a momentary pause for reflection.

\section{Conflict of interest statement}

The authors have no conflicts of interest to declare.

\section{References}

1. Kereiakes DJ, Ellis SG, Metzger C, Caputo RP, Rizik DG, Teirstein PS, Litt MR, Kini A, Kabour A, Marx SO, Popma JJ, McGreevy R, Zhang Z, Simonton C, Stone GW; ABSORB III Investigators. 3-Year Clinical Outcomes With Everolimus-Eluting Bioresorbable Coronary Scaffolds: The ABSORB III Trial. J Am Coll Cardiol. 2017;70:2852-62.

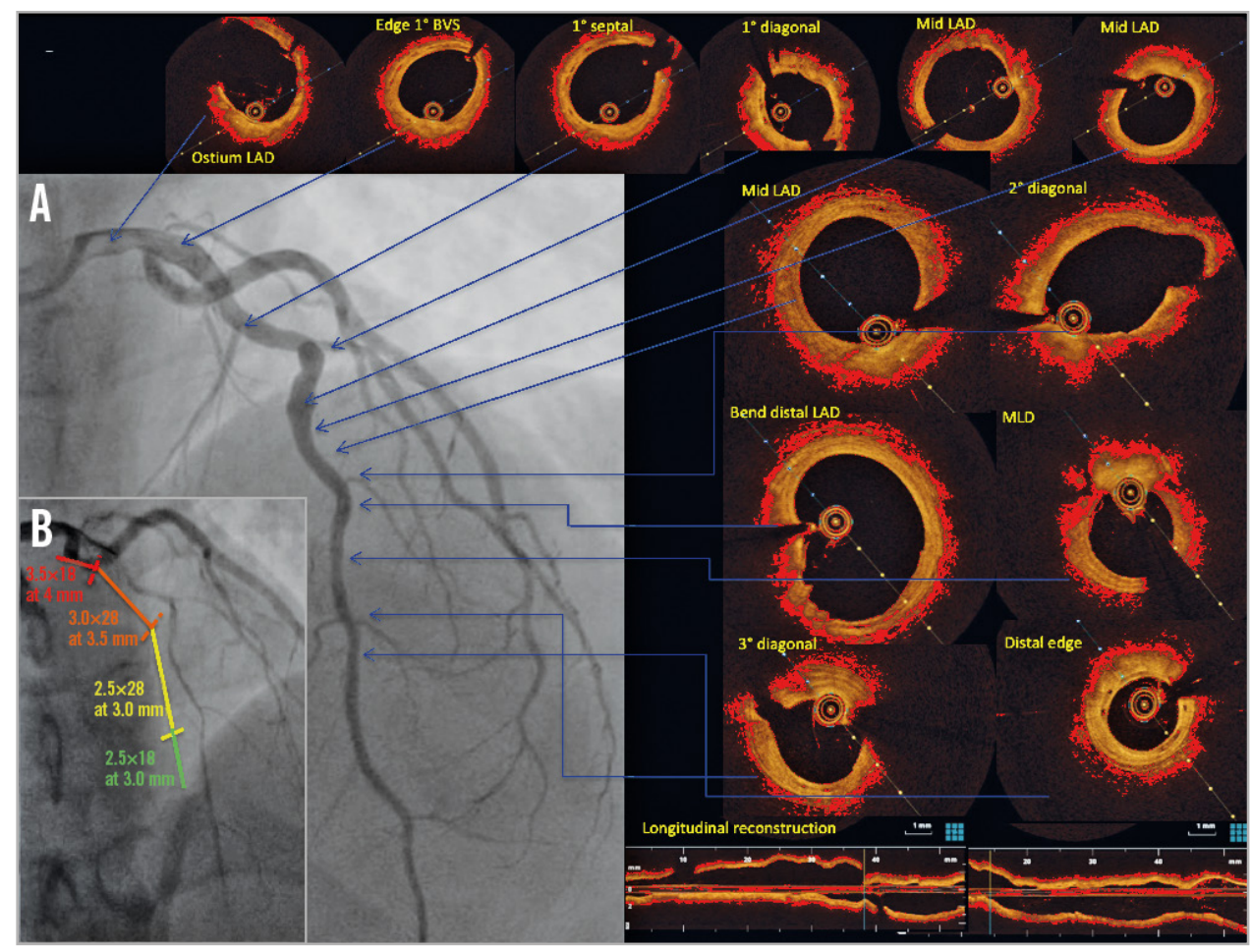

Figure 2. Diffuse LAD atherosclerosis and long-term follow-up after scaffold resorption. Angiographic follow-up at four years (A) and detail of the vessel segments implanted with BVS (B). OCT scan from the left main to the distal LAD: some residual black boxes of the most proximal scaffold are still embedded in the artery wall. The arterial wall shows a normal three-layer structure with no images of excessive neointimal proliferation, thrombus, or residual polymeric struts all along the mid and distal LAD, due to the complete resorption of the struts. The positive remodelling of the vessel area is also clearly shown throughout the OCT-scanned length. 
2. Tijssen RYG, Kraak RP, Hofma SH, van der Schaaf RJ, Arkenbout EK, Weevers A, Elias J, van Dongen IM, Koch KT, Baan J Jr, Marije Vis M, de Winter RJ, Piek JJ, Tijssen JGP, Henriques JPS, Wykrzykowska JJ. Complete two-year follow-up with formal non-inferiority testing on primary outcomes of the AIDA trial comparing the Absorb bioresorbable scaffold with XIENCE drug-eluting metallic stent in routine PCI. EuroIntervention. 2018;14:e426-33.

3. Serruys PW, Onuma Y. Dmax for sizing, PSP-1, PSP-2, PSP-3 or OCT guidance: interventionalist's jargon or indispensable implantation techniques for short- and long-term outcomes of Absorb BRS? EuroIntervention. 2017;17:2047-56.

4. Stone GW, Abizaid A, Onuma Y, Seth A, Gao R, Ormiston J, Kimura T, Chevalier B, Ben-Yehuda O, Dressler O, McAndrew T, Ellis SG, Kereiakes DJ, Serruys PW. Effect of Technique on Outcomes Following Bioresorbable Vascular Scaffold Implantation: Analysis From the ABSORB Trials. J Am Coll Cardiol. 2017;70: 2863-74.

5. Tijssen RYG, Kraak RP, Elias J, van Dongen IM, Kalkman DN, Nassif M, Sotomi Y, Asano T, Katagiri Y, Collet C, Piek JJ, Henriques JPS, de Winter RJ, Tijssen JGP, Onuma Y, Serruys PW,
Wykrzykowska JJ. Implantation techniques (predilatation, sizing, and post-dilatation) and the incidence of scaffold thrombosis and revascularisation in lesions treated with an everolimus-eluting bioresorbable vascular scaffold: insights from the AIDA trial. EuroIntervention. 2018;14:e434-42.

6. Capranzano P, Testa L, Tamburino C, Capodanno D, BiondiZoccai G, Longo G, Tomai F, Ribichini F, Indolfi C, Bartorelli AL, Petronio AS, Bedogni F, La Manna A, Francaviglia B, De Carlo M, Tamburino C. [Technical features of Absorb(TM) BVS implantation in the IT-DISAPPEARS registry]. [Article in Italian]. G Ital Cardiol (Rome). 2014;15:475-81.

7. Testa L, De Carlo M, Petrolini A, Rapetto C, Varbella F, Cortese B, Gabrielli G, Geraci S, Loi B, Boccuzzi G, Tarantini G, Fischetti D, Calabria P, Tomai F, Ribichini F, Tamburino C, Indolfi C, Bartorelli AL, Petronio AS, Bedogni F. One-year clinical results of the Italian diffuse/multivessel disease ABSORB prospective registry (IT-DISAPPEARS). EuroIntervention. 2017;13: 424-31.

8. Ribichini F. Rationale for the use of bioresorbable vascular scaffolds. Why bioresorbable technology is the future of endovascular therapeutics. Minerva Cardioangiol. 2016;64:399-403. 